GAD-7. Không có mối liên quan có ý nghĩa thống kê giữa lo âu với giai đoạn bệnh ung thư. Nghiên cứu của Medeiros cũng cho thấy tỷ lệ ung thư giai đoạn III là phổ biến nhất nhưng không có mối liên quan giữa giai đoạn bệnh và lo âu [8]. Tuy nhiên, dù ở giai đoạn nào thì người bệnh ung thư đường tiêu hóa cũng có nguy cơ mắc lo âu do gánh nặng bệnh tật và suy giảm thể chất, do vậy chăm sóc bệnh nhân ung thư đường tiêu hóa cân chú ý nhận biết lo âu để can thiệp kịp thời, nhằm tăng hiệu quả điều trị và chất lượng sống cho bệnh nhân.

\section{KẾT LUẦN}

Nghiên cứu 124 bệnh nhân ung thư đường tiêu hóa tại Bệnh viện $K$ từ tháng 8/2020 đến 10/2020 chúng tôi có nhận xét sau: Đa số bệnh nhân là nam giới, tuổi trung niên. Theo thang GAD-7, có $30,6 \%$ bệnh nhân ung thư tiêu hóa có lo âu, nhiều nhất ở ung thư dạ dày và giai đoạn III-IV. Có mối liên quan có ý nghĩa thống kê giữa lo âu với tuổi và thời gian chẩn đoán bệnh. Không có mối liên quan giữa lo âu với vị trí và giai đoạn ung thứ.
TÀI LIỆU THAM KHẢO

1. International Agency for Research on Cancer W.H.O. (2020). Vietnam fact sheets. Globocan 2020.

2. (2012). NCCN Clinical Practice Guidelines in Oncology

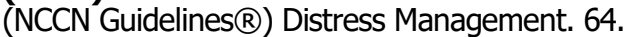

3. Holland J.C., Golant M., Greenberg D.B. và cô̂ng sự. Psycho-Oncology: A Quick Reference on the Psychosocial Dimensions of Cancer Symptom Management. 249.

4. Bektas D.K. và Demir S. (2016). Anxiety, Depression Levels and Quality of Life in Patients with Gastrointestinal Cancer in Turkey. Asian Pacific Journal of Cancer Prevention, 17(2), 723-731.

5. Han L. (2020). Prevalence, risk factors and prognostic role of anxiety and depression in surgical gastric cancer patients. Translational Cancer Research, 9(3).

6. Matsushita T., Matsushima E., và Maruyama M. (2005). Anxiety and depression of patients with digestive cancer. Psychiatry Clin Neurosci, 59(5), 576-583.

7. Tavoli A., Mohagheghi M.A., Montazeri A. và cộng sự. (2007). Anxiety and depression in patients with gastrointestinal cancer: does knowledge of cancer diagnosis matter?. BMC Gastroenterol, 7, 28.

8. Medeiros M., Oshima C.T.F., và Forones N.M. (2010). Depression and anxiety in colorecta cancer patients. J Gastrointest Cancer, 41(3), 179-184.

\title{
CHI PHÍ TRỰC TIẾP ĐIỀU TRỊ UNG THƯ VÚ TẠI VIÊTT NAM, NĂM 2019
}

\section{TÓM TẮT}

Mục tiêu: Nghiên cứu được thực hiện nhằm đo lường chi phí trực tiếp điều trị ung thư vú tại Viêt Nam năm 2019. Phương pháp nghiên cứu: N̉ghiển cứu mô tả cắt ngang, dưa trên hồi cứu số liệu từ hồ sơ thanh toán khi ra viện và phỏng vấn 87 người bệnh ung thư vú hoàn thành đợt điều trị trong thới gian thu thập số liệu của nghiên cứu, từ tháng 12/2019 đến tháng 6/2020 tại bệnh viện $K$ Trung Ương. Kết quả và kết luận: Nghiển cứu cho thấy, đợt điều trị hiện tại, tổng chi phí trực tiếp điều trị ung thư vú vào khoảng 17.657.000 VNĐ với chi phí thấp nhất là 3.188.000 VNĐ và chi phí cao nhất là 85.529.000 VNĐ. Đối với tổng chi phí trong năm 2019, tổng chi phí trực tiếp trung bình lên đến tổng chi phí trực tiếp vào khoảng 135.289.000 VNĐ với chi phí thấp nhất là 3.188.000 VNĐ và chi phí cao nhất là 923.221.000 VNĐ. Trong các nhóm chi phí, chi phí tiền túi hộ gia đình đều chiếm tỷ trọng lớn hớn.

*Trường Đại học Y tế Công Cộng

Chịu trách nhiệm chính: Nguyễn Quỳnh Anh

Email: nqa@huph.edu.vn

Ngày nhận bài: 2.3.2021

Ngày phản biên khoa hoc: 26.4 .2021

Ngày duyệt bài: 10.5.2021

\section{Nguyễn Quỳnh Anh*, Nguyễn Thu Hà*}

Tư khoá: Chi phí điều trị trực tiếp, ung thư vú, Việt Nam

\section{SUMMARY \\ DIRECT COST OF BREAST CANCER TREATMENT IN VIETNAM, 2019}

Objective: To measure the direct cost of breast cancer treatment in Vietnam in 2019. Methods: Cross-sectional descriptive study, based on retrospective billing data from hospital discharge records and interviews with 87 breast cancer patients who completed treatment during data collection of the study, from December 2019 to June 2020 at Vietnam National Cancer Hospital. Results and conclusions: During the current treatment, the total direct cost was about 17,657,000 VND with the lowest cost of $3,188,000$ VND and the highest cost of $85,529,000$ VND. For total costs in 2019, the average total direct costs amount to VND 135,289,000 with the lowest cost of VND $3,188,000$ and the highest cost of VND $923,221,000$. Among the cost groups, household outof-pocket expenses accounted for a larger share.

Keywords: Direct treatment costs, breast cancer, Vietnam

\section{I. ĐẶT VẤN ĐỀ}

Sự gia tăng của bệnh ung thư cùng với thực 
trạng đa số các trường hợp mắc được phát hiện khi đã ở giai đoạn muộn dânn đến tỷ lệ tàn tật và tử vong cao và gánh nặng kinh tế lớn cho người bệnh, cho hệ thống chăm sóc sức khỏe và toàn xã hội, đặc biệt là đối với các quốc gia có thu nhập thấp và trung bình (1). Đo lường chi tiết, đầy đủ và chính xác gánh nặng kinh tế của ung thư là một trong những điều kiện cơ bản để có thể xây dựng chương trình phòng chống ung thư có hiệu quả, giúp giảm tỷ lệ mắc và tử vong $(2,3)$.

Ung thư vú (UTV) là bệnh ung thư hay gặp nhất ở phụ nữ và là nguyền nhân gây tử vong cao tại các nước trên thế giới. Tại Việt Nam, theo nghiên cứu gánh nặng bệnh ung thư và chiến lược phòng chống ung thư quốc gia đến năm 2020 cho thây UTV là bệnh có tỷ lệ mới mắc cao nhất trong các ung thư ở nữ giới (4).

Tại Việt Nam, giá dịch vụ khám bệnh, chữa bệnh đã có những thay đổi nhất định, đặc biệt cùng với sự áp dụng của Thông tư 15/2018/TTBYT, thông tư 37/2018/TT-BYT và Thông tư 39/2018/TT-BYT. Vì những lý do trên, nhằm cung cấp những bằng chứng đáng tin cậy giúp huy động và phân bổ nguồn lực trong kiểm soát ung thư cũng như làm tiền đề cho các nghiên cứu về kinh tế y tế trong thời gian tới, nhóm nghiên cứu tiến hành đề tài nghiên cứu "Đo lường chi phí điều trị trực tiếp của ung thư vú tại Việt Nam năm 2019".

\section{II. ĐỐI TƯợNG VÀ PHƯƠNG PHÁP NGHIÊN CỨU}

Thiết kế nghiên cứu: Nghiên cứu cắt ngang sử dụng số liệu định lượng

Đối tượng nghiên cứu: Được chẩn đoán mắc ung thư vú (Breast, C50), tại thời điểm tiến hành phỏng vấn, người bệnh được chỉ định là đã hoàn thành đợt điều trị hiện tai

Thời gian và địa điểm nghiên cứu: từ tháng 12/2019 đến tháng 6/2020 tại bệnh viện K TW.

Cõ̃ mẫu: Áp dụng công thức tính cỡ mẫu ước lượng giá trị trung bình

$$
\mathrm{N}=\frac{z_{1-\infty / 2}^{2} \sigma^{2}}{\varepsilon^{2} \mu \mu^{2}}
$$

$\mathrm{N}$ : Là số đối tượng cần điều tra, Z: Hệ số tin cậy (Với độ tin cậy $95 \%$ thì giá trị của $Z=1,96$ ), б: Giá trị ước lượng của độ lệch chuẩn của đặc tính nghiên cứu trong quần thể, $\varepsilon$ : Độ chính xác tương đối, $\mu$ : Giá trị trung bình của đặc tính nghiên cứu trong quần thể

Sử dụng số liệu của bệnh ung thư vú trong nghiên cứu khác (5) với $\mu=173$ triêuu đồng và $\sigma$ $=143$ triệu đồng; lấy $\varepsilon=0,2$ thì số lượng người bệnh ung thư cần thiết đưa vào nghiên cứu ước tính cho nhóm bệnh ung thư vú là $\mathrm{N}=66$. Thực tế thu thập được số liệu trên 87 người bệnh

Phương pháp thu thập số liệu: Sử dụng Bảng hỏi có cấu trúc để phỏng vẩn toàn bộ người bênh ung thư thỏa mãn tiêu chí nghiên cứu chuẩn bị ra viện vào thời điểm diễn ra nghiên cứu, Bảng kiểm có sẵn để thu thập thông tin liên quan đến số lượng dịch vụ sử dụng và chi phí điều trị của người bệnh được thu thâpp từ phiếu thanh toán ra viên của bệnh nhân. Các nhóm chi phí được thu thập bao gồm: C1 - Chi phí trực tiếp dành cho y tế - từ phía CSYT/Chính phủ, C2 - Chi phí trực tiếp dành cho y tế - từ phía người bênhh/BHYT, C3 - Chi phí trực tiếp không dành cho y tế - từ phía người bệnh, C4 - Chi phí trực tiếp không dành cho y tế - từ phía gia đình.

Quản lý và phân tích số liệu: Số liệu được nhập bằng phần mềm Excel 2007 cho phần thông tin liên quan đến bệnh viện và phần mềm Epi data 3.1 cho các thổng tin liên quan đênn người bệnh.

Đạo đức nghiên cứu: Nghiên cứu tuân thủ quy trình xét duyệt của Hội đồng nghiên cứu khoa học Trường Đại học Y tế công cộng.

\section{KẾT QUẢ NGHIÊN CỨU}

1. Thông tin chung của đôi tượng nghiên cứu

Bảng 1: Mô tả các thông tin cơ bản về người bệnh tham gia trả lời phỏng vấn

\begin{tabular}{|c|c|c|}
\hline Đặc điểm & $\begin{array}{c}\text { Tấn } \\
\text { số (n) }\end{array}$ & $\begin{array}{c}\text { Tỷ lệ } \\
(\mathbf{\%})\end{array}$ \\
\hline Nhóm tuối: $15-30$ & 4 & $4,6 \%$ \\
\hline $31-45$ & 25 & $28,7 \%$ \\
\hline $46-60$ & 47 & $54,0 \%$ \\
\hline$>60$ & 11 & $12,7 \%$ \\
\hline Giới tính: Nữ & 87 & $100 \%$ \\
\hline Nam & 0 & $0 \%$ \\
\hline
\end{tabular}

Tình trạng hôn nhân

\begin{tabular}{|c|c|c|}
\hline Chưa kết hôn & 6 & $6,9 \%$ \\
\hline Đã kết hôn & 77 & $88,5 \%$ \\
\hline Góa & 2 & $2,3 \%$ \\
\hline Ly dị/ly thân & 2 & $2,3 \%$ \\
\hline \multicolumn{2}{|c|}{ Trình độ học vấn } \\
\hline Chưa hết tiếu học & 8 & $9,2 \%$ \\
\hline Hết tiếu học & 13 & $14,9 \%$ \\
\hline Hết trung học cớ sở & 18 & $20,7 \%$ \\
\hline Hết trung học phố thông & 21 & $24,1 \%$ \\
\hline Cao đằng, trung cấp nghề & 21 & $24,1 \%$ \\
\hline Đại học và trên đại học & 6 & $7,0 \%$ \\
\hline
\end{tabular}

Tình trạng làm việc hiện tại

\begin{tabular}{|l|l|l}
\hline Thất nghiệp/không làm việc & 20 & $23,0 \%$ \\
\hline
\end{tabular}

\begin{tabular}{|c|c|c|}
\hline Hưu trí & 16 & $18,4 \%$ \\
\hline Dang có việc làm & 51 & $58,6 \%$ \\
\hline BHYT: Không & 2 & $2,3 \%$ \\
\hline Có & 85 & $97,7 \%$ \\
\hline
\end{tabular}


Tổng số người bệnh ung thư vú tham gia trả lời phỏng vấn là 87 người bệnh. Về độ tuổi, độ tuổi trung bình của người bệnh tham gia phỏng vấn là $50,0( \pm 10,9)$ với độ tuổi thấp nhất là 25 tuổi và độ tuổi cao nhất là 80 tuổi, đa số người bệnh tham gia trả lời phỏng vấn đã kết hôn $(88,5 \%)$. Thu nhập hộ gia đình của nhóm người bệnh ung thư vú là 90.156 .000 đồng/năm. Số ngày điều trị trung bình là 59,1 ngày dao động từ 3 đến 298 ngày.
2. Chi phí điêuu trị ung thư vú tại Việt Nam năm 2019. Bảng 2 mô tả chi phí trung bình của người bệnh ung thư vú trong nghiên cứu. Trong đợt điều trị hiện tại, tổng chi phí trực tiếp vào khoảng 17.657.000 VNĐ với chi phí thấp nhất là 3.188.000 VNĐ và chi phí cao nhất là 85.529.000 VNĐ. Giá trị Q1 là 8.678.000 VNĐ, chi phí trung vị cho đợt điều trị hiện tại là 14.413.000 VND và giá trị Q3 tương ứng là 21.118.000 VNĐ.

\section{Bảng 2: Chi phí trung bình của người bệnh ung thư vú trong nghiên cứu}

\begin{tabular}{|c|c|c|c|c|c|c|c|}
\hline & Mean & SD & Min & Q1 & Median & Q3 & Max \\
\hline \multicolumn{8}{|c|}{ Chi phí cho đợt điêuu trị hiện tại } \\
\hline Chi tiền túi hộ gia đình & 10.383 & 10.157 & 0 & 3.066 & 7.021 & 13.902 & 58.695 \\
\hline Chi phí BHYT & 7.274 & 6.065 & 0 & 3.838 & 5.362 & 9.202 & 27.691 \\
\hline Tống chi trực tiếp & 17.657 & 14.490 & 3.188 & 8.678 & 14.413 & 21.118 & 83.529 \\
\hline \multicolumn{8}{|c|}{ Tống chi phí trong năm 2019 } \\
\hline Chi tiền túi hộ gia đình & 75.692 & 130.305 & 0 & 18.615 & 39.440 & 82.311 & 873.488 \\
\hline Chi phí BHYT & 59.596 & 104.317 & 0 & 8.150 & 24.575 & 59.769 & 684.402 \\
\hline Tống chi trực tiếp & 135.289 & 182.327 & 3.188 & 34.334 & 67.799 & 147.928 & 923.221 \\
\hline
\end{tabular}

Đối với tổng chi phí trong năm 2019, tổng chi phí trực tiếp trung bình lên đến tổng chi phí trực tiếp vào khoảng 135.289.000 VNĐ với chi phí thấp nhất là 3.188.000 VNĐ và chi phí cao nhất là 923.221.000 VNĐ. Giá trị Q1 là 34.334 .000 VNĐ, chi phí trung vị cho đợt điều trị hiện tại là 67.799.000 VND và giá trị Q3 tương ứng là 147.928.000 VND.

Hình 1 minh họa các cấu phần chi phí trong tổng chi phí cho đợt điều trị hiện tại và tổng chi phí trong năm 2019. Trong đó tổng chi phí trong năm 2019 lớn gấp 7.7 lần so với chi phí của đợt điều trị hiện tại. Trong các nhóm chi phí, chi phí tiền túi hộ gia đình đều chiếm tỷ trọng lớn hơn. Cụ thể, đối với chi phí cho đợt điều trị hiện tại, chi phí tiền túi hộ gia đình và chi phí từ phía BHYT lần lượt chiếm $58,8 \%$ và $41,2 \%$. Đối với chi phí trong năm 2019, chi phí tiền túi hộ gia đình và chi phí từ phía BHYT lần lượt chiếm $55,9 \%$ và $44,1 \%$.

Bảng 3: Tỷ lệ các nhóm chi phí của người bệnh ung thư vú trong nghiên cứu phân theo lân nhập viện điều trị

\begin{tabular}{|c|c|c|c|c|}
\hline 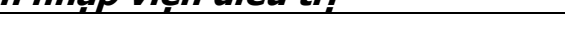 & Chi phí trung bình & Tỷ lệ \% & LCI & HCI \\
\hline \multicolumn{5}{|c|}{ Điều trị lần đầu } \\
\hline \multicolumn{5}{|l|}{ Chi phí cho đợt điều trị hiện tại } \\
\hline Chi tiền túi hộ gia đình & 15.542 & $58,4 \%$ & 10.198 & 20.887 \\
\hline Chi phí BHYT & 11.091 & $41,6 \%$ & 7.662 & 14.518 \\
\hline Tống chi trực tiếp & 26.633 & $100,0 \%$ & 18.764 & 34.502 \\
\hline \multicolumn{5}{|l|}{ Tống chi phí trong năm 2019} \\
\hline Chi tiền túi hộ gia đình & 96.678 & $50,3 \%$ & 39.398 & 153.958 \\
\hline Chi phí BHYT & 95.440 & $49,7 \%$ & 35.677 & 155.202 \\
\hline Tống chi trực tiếp & 192.118 & $100,0 \%$ & 108.030 & 276.205 \\
\hline \multicolumn{5}{|c|}{ Điều trị tái phát } \\
\hline Chi phí cho đợt điều trị hiện tại & & & & \\
\hline Chi tiền túi hộ gia đình & 7.186 & $53,3 \%$ & 5.501 & 8.871 \\
\hline
\end{tabular}


VIETNAM MEDICAL JOURNAL N²2 - MAY - 2021

\begin{tabular}{|c|c|c|c|c|}
\hline Chi phí BHYT & 6.286 & $46,7 \%$ & 5.527 & 7.045 \\
\hline Tống chi trực tiếp & 13.472 & $100,0 \%$ & 11.576 & 15.368 \\
\hline \multicolumn{5}{|c|}{ Tống chi phí trong năm 2019} \\
\hline Chi tiền túi hộ gia đình & 42.295 & $60,8 \%$ & 29.876 & 54.714 \\
\hline Chi phí BHYT & 27.249 & $39,2 \%$ & 19.045 & 35.452 \\
\hline Tông chi trực tiếp & 69.544 & $100,0 \%$ & 49.917 & 89.169 \\
\hline \multicolumn{5}{|c|}{ Điều trị giai đoạn cuốí } \\
\hline \multicolumn{5}{|c|}{ Chi phí cho đợt điều trị hiện tại } \\
\hline Chi tiền túi hộ gia đình & 8.659 & $65,0 \%$ & 5.510 & 11.808 \\
\hline Chi phí BHYT & 4.668 & $35,0 \%$ & 3.464 & 5.872 \\
\hline Tống chi trực tiếp & 13.327 & $100,0 \%$ & 9.583 & 17.070 \\
\hline \multicolumn{5}{|c|}{ Tống chi phí trong năm 2019} \\
\hline Chi tiền túi hộ gia đình & 88.390 & $60,6 \%$ & 26.693 & 150.086 \\
\hline Chi phí BHYT & 57.412 & $39,4 \%$ & 25.258 & 89.565 \\
\hline Tống chi trực tiếp & 145.801 & $100,0 \%$ & 66.876 & 224.725 \\
\hline
\end{tabular}

Bảng 3 mô tả giá trị $95 \%$ khoảng tin cậy của tổng chi phí trực tiếp năm 2019 của người bệnh ung thư vú phẩn theo lần nhập viện điêu trị. Với người bệnh nhập viện điều trị lần đầu, trung bình của tổng chi phí trực tiếp của đợt điều trị hiện tại là 26.633 .000 đồng, $95 \%$ CI dao động từ 18.764.000 đồng đến 34.502.000 đồng. Chi phí tiền túi hộ gia đình trong đợt điều trị hiện tại trung bình là 15.542 .000 đồng, $95 \% \mathrm{CI}$ dao động từ 10.198.000 đồng đến 20.887.000 đồng. Chi phí từ phía BHYT trong đợt điều trị hiện tại trung bình là 11.091 .000 đồng, $95 \%$ CI dao động từ 7.662.000 đồng đến 14.518.000 đồng. Đối với tổng chi phí trong năm 2019, 95\% khoảng tin cậy của tổng chi phí trực tiếp rơi vào khoảng từ 108.030.000 đồng đến 276.205.000 đồng. Trong đó, 95\% khoảng tin cậy của chi phí tiền túi hộ gia đình là 39.398.000 - 153.958.000 đồng. Tương tự đối với chi phí từ phía bảo hiểm y tế có $95 \%$ CI là 35.677.000 - 155.202.000 đồng.

Với người bệnh nhập viện điêuu trị tái phát, trung bình của tổng chi phí trực tiếp của đợt điêuu trị hiện tại là 13.472 .000 đồng, 95\% CI dao động từ 11.576 .000 đồng đến 15.368 .000 đồng. Chi phí tiền túi hộ gia đình trong đợt điều trị hiên tại trung bình là 7.186 .000 đồng, $95 \% \mathrm{CI}$ dao động từ 10.198.000 đồng đến 20.887.000 đồng. Chi phí từ phía BHYT trong đợt điều trị hiện tại trung bình là 11.091 .000 đồng, $95 \% \mathrm{CI}$ dao động từ 5.501.000 đồng đến 8.871 .000 đồng. Đối với tổng chi phí trong năm 2019, 95\% khoảng tin cậy của tổng chi phí trực tiếp rơi vào khoảng từ 49.917.000 đồng đển 89.169.000 đồng. Trong đó, $95 \%$ khoảng tin cậy của chi phí tiền túi hộ gia đình là 29.876.000 - 54.714.000 đồng. Tương tự đối với chi phí từ phía bảo hiểm y tế có $95 \%$ CI là 19.045 .000 - 35.452.000 đồng.

Với người bênh nhập viện điêuu trị giai đoan cuối trung bình của tổng chi phí trực tiếp của đợt điều trị hiện tại là 13.327 .000 đồng, $95 \% \mathrm{CI}$ dao động từ 9.583.000 17.070000 đồng. Chi phí tiền túi hộ gia đình trong đợt điều trị hiện tại trung bình là 8.659 .000 đồng, $95 \%$ CI dao động từ 5.510 .000 - 11.808.000 đồng. Chi phí từ phía BHYT trong đợt điều trị hiện tại trung bình là 4.668.000 đồng, $95 \%$ CI dao động từ 3.464.000 5.872 .000 đồng. Đối với tổng chi phí trong năm 2019, 95\% khoảng tin cậy của tổng chi phí trực tiếp rơi vào khoảng từ $66.876 .000-224.725 .000$ đồng. Trong đó, $95 \%$ khoảng tin cậy của chi phí tiền túi hộ gia đình là 26.693.000 - 150.086 .000 đồng. Tướng tự đối với chi phí từ phía bảo hiểm y tế có 95\% CI là 25.258.000 - 89.565.000 đồng.

\section{BÀN LUÂ̂N}

Nghiên cứu cho thấy, đợt điều trị hiên tai, tổng chi phí trực tiếp điều trị ung thư vú vào khoảng 17.657.000 VNĐ với chi phí thấp nhất là 3.188.000 VNĐ và chi phí cao nhất là 85.529.000 VNĐ. Đối với tổng chi phí trong năm 2019, tổng chi phí trực tiếp trung bình lên đến tổng chi phí trực tiếp vào khoảng 135.289.000 VNĐ với chi phí thấp nhất là 3.188.000 VND và chi phí cao nhất là 923.221.000 VNĐ. Trong các nhóm chi phí, chi phí tiền túi hộ gia đình đều chiếm tỷ trọng lớn hơn. Nghiên cứu chi phí bệnh tật của ung thư được thực hiện nhiều tại các nước phát triển, đặc biệt là Mỹ. Một nghiên cứu gần đây tại Mỹ (6) đã ước tính tổng chi phí y tế trên quy mô quốc gia cho 13 nhóm bệnh ung thư ở nam giới và 16 nhóm bệnh ung thư ở nữ giới trong năm 2010 và dự báo tổng chi phí vào năm 2020, dựa trên các số liệu cập nhật nhất về tỷ lệ mới mắc, tỷ lệ sống sót và chi phí y tế. Trong đó, chi phí y tế của ung thư vú (nữ giới) là cao nhất (16.50 tỷ đôla $M y ̃)$, tiếp đến là ung thư đại trực tràng (14.14 tỳ đôla Mỹ), ung thư hạch (12.14 tỷ đôla Mỹ), ung thư phổi (12.12 tỷ đôla Mỹ) và ung thư 
tuyến tiền liệt (11.85 tỷ đôla Mỹ). Một ví dụ tốt hơn cho một nghiên cứu chi phí bệnh tật của ung thư trong đó tính toán đây đủ 4 nhóm chi phí (chi phí trực tiếp, chi phí do tàn tật, chi phí do tử vong và chi phí vô hình) là nghiên cứu đo lường chi phí của ung thư vú ở nữ giới tại Thuy. Điển năm 2002 (7). Tổng chi phí của bệnh ung thư vú tại Thuy. Điển vào năm 2002 được ước tính là 3.0 tỷ SEK. Trong đó, chi phí gián tiếp (chi phí do nghỉ việc/về hưu sớm và chi phí do tử vong sớm) chiếm hơn 2/3 tổng gánh nặng kinh tế của bệnh. Tại Việt Nam, nghiên cứu Đánh giá gánh nặng kinh tế của một số bệnh ung thư phổ biến được thực hiện từ năm 2012 (5). Với góc độ tính toán chi phí từ cả phía chính phủ và hộ gia đình, nghiên cứu đề cập một cách toàn diện tất cả các nhóm chi phí bao gồm: (1) chi phí trực tiếp dành cho y tế; (2) chi phí gián tiếp dành cho y tế; (3) chi phí trực tiếp không dành cho y tế; (4) Chi phí gián tiếp không dành cho y tế; (5) Chi phí cơ hội do giảm năng suất lao động và (6) Chi phí cơ hội do tử vong sớm. Kết quả nghiên cứu cho thâyy, ung thư vú có chi phí điều trị trung bình trong năm 2012 là 209.806.000 VNĐ (95\%CI: 177.223.000 VNĐ - 242.389.000 VNĐ). Gánh nặng kinh tế của ung thư vú trên thực tế còn bao gồm cả gánh nặng kinh tế của ung thư vú đối với nam giới, tuy nhiên trong nghiên cứu này do hạn chế trong việc tiếp cận thu thập số liêu từ người bênh là nam giới khiến nhóm nghiên cứu chỉ ước tính gánh nặng kinh tế của ung thư vú ở nữ giới. Tuy nhiên, việc sử dụng giả định này có thể khiến cho tổng gánh nặng kinh tế trong nghiên cứu này có thể thấp hơn tổng gánh nặng kinh tế trên thực tế chứ không làm ước lượng quá gánh nặng thực tế.

\section{KẾT LUẬN}

Nghiên cứu cho thây, đợt điều trị hiện tại, tổng chi phí trực tiếp điều trị ung thư vú vào khoảng 17.657.000 VNĐ với chi phí thấp nhất là 3.188.000 VNĐ và chi phí cao nhất là 85.529.000 VNĐ. Đối với tổng chi phí trong năm 2019, tổng chi phí trực tiếp trung bình lên đến tổng chi phí trực tiếp vào khoảng 135.289.000 VNĐ với chi phí thấp nhất là 3.188.000 VNĐ và chi phí cao nhất là 923.221.000 VNĐ. Trong các nhóm chi phí, chi phí tiền túi hộ gia đình đều chiếm tỷ trọng lớn hơn.

\section{TÀI LIẸU THAM KHẢO}

1. Nguyễn Thanh Hương và cộng sự Báo cáo đề tâi cấp bộ: Tuổi thọ khỏe mạnh và gánh nặng bệnh tật tại Việt Nam năm 2015, Hà Nội.

2. Nguyển Thanh Hương và cộng sự Báo cáo đề tài cấp bộ: Tuổi thọ khỏe mạnh và gánh nặng bệnh tật tại Việt Nam năm 2015, Hà Nội.

3. Nguyến Tịị Trang Nhung, Trân Khánh Long, Bùi Ngoc Lính và cộng sứ. (2010), Gánh nặng bệnh tật và chấn thương ở Việt Nam, Nhà xuất bán y học, Hà Nội.

4. Bùi Diệu, Nguyền Bá Đức, Trân Văn Thuấn và cộng sự (2012). Gánh nặng bệnh ung thư và chiến lược phòng chống ung thư quốc gia đến năm 2020. Tạp Chí Ung Thư Học, 1, 13-19

5. Nguyến Quỳnh Anh và Nguyễn Thu Hà (2014), Báo cáo đề tài nghiên cứu cấp cơ sở: Gánh nặng kinh tế của 6 bệnh ung thư phổ biến tai Viêt Nam,

6. Mariotto A.B., Robin Yabroff $K_{\text {., }}$ Shao Y. và cộng sự. (2011). Projections of the cost of cancer care in the United States: 2010-2020. J Natl Cancer Inst, 103(2), 117-128.

7. Lidgren M., Wilking N., và Jönsson B. (2007). Cost of breast cancer in Sweden in 2002. Eur J Heal Econ, 8(1), 5-15.

\section{THỰC TRANG KIẾN THỨC VỀ QUẢN LÝ CỦA CÁC ĐIỀU DƯỠNG TRƯỞNG KHOA LÂM SÀNG CỦA MỘT Số BÊ̂NH VIÊ̂N CÔNG LẬP TUYẾN TỈNH LAO CAI, 2020}

\section{TóM TẮT}

Năng lực quản lý của điều dưỡng trưởng là một yếu tố quan trọng để tận dụng mọi nguồn lực tại khoa và bệnh viện để phục vụ và chẳm sóc người bệnh.

\footnotetext{
${ }^{1}$ Trường Đại học Y tế công cộng

Bênh viện đa khoa tỉnh Lào Cai

Chịu trách nhiệm chính: Nguyễn Ngọc Bích

Email: nnb@huph.edu.vn

Ngày nhân bài: 8.3.2021

Ngày phản biên khoa hoc: 27.4.2021

Ngày duyệt bài: 11.5.2021
}

\section{Nguyễn Ngọc Bích ${ }^{1}$, Lù Tà Phìn ${ }^{2}$}

Nghiên cứu mô tả thực trạng kiến thức quản lý của điêu dưỡng trưởng các khoa lâm tai các bênh viên công lập tuyến tỉnh Lào Cai được triển khai năm 2020. Thiết kế nghiên cứu cắt ngang thực hiện tại 05 Bệnh viện tuyến tỉnh của tỉnh Lào Cai từ tháng $6 / 2020$ 11/2020. Số liệu định lượng thu thập từ bộ câu hỏi phát vấn 54 cán bộ y tế là điều dưỡng trưởng các khoa lâm sàng, nghiên cứu cũng đã tiến hành phỏng vấn sâu trên các điều dưỡng trưởng.Kết quả nghiên cứu cho thấy kiến thức chung về quản lý của điều dưỡng trưởng khoa còn thấp, chỉ có $44,4 \%$ điều dưỡng trưởng đáp ứng về kiến thức quản lý điều dưỡng. Việc xây dựng quy hoạch điều dưỡng trưởng 